\title{
Evaluation of Tomato Cultivars for Central Tarai of Nepal
}

\author{
Surendra Lal Shrestha ${ }^{1}$ and Raj Lal Sah ${ }^{2}$ \\ ${ }^{l}$ Horticulture Research Division, Nepal Agriculture Research Council, Laitpur Nepal \\ ${ }^{2}$ Regional Agriculture Research Station, Parwanipur, Nepal \\ e-mail: shsurendra@hotmail.com
}

\begin{abstract}
Tomato (Lycopersicon esculentum L.) is an important winter vegetable crop in Central Tarai. As compared to India (25 t/ha), the productivity of this crop in this area is quite low (17 t/ha). One of the major contributing factors of low productivity of tomato is the lack of suitable high yielding varieties under rice based cropping system. Ten tomato cultivars, 3 released check cultivars (Pusa ruby and CL-1131 open pollinated and Srijana hybrid cultivar), 7 superior cultivars from Initial Evaluation Trial in the past were planted in November 2005, 2006, 2009 and 2010 at RARS Parwanipur in rice-based cropping system. The trial was laid out in a randomized complete block design with four replications. Seedlings were transplanted on beds at 60x60 cm spacing fertilized with 120:100:60 NPK $+15 \mathrm{t}$ compost per hectare. Results showed that cv. HRDTOM-005XHRDTOM-010 (30.64 t/ha) followed by Makis (28.90 t/ha) and cv. Srijana (28.87 t/ha) gave higher yield among the tested cultivars. These cultivars had given $47.0 \%, 38.7 \%$, and $38.5 \%$ more yield as compared to commercial hybrid variety Manisha (20.84t/ha) whereas Bari-4 and CL-1131 had superior performance among the tested open pollinated cultivars. On the basis of overall performance, cultivars, HRDTOM-005XHRDTOM-010, Makis and Srijana hybrid cultivars, and Bari-4 and CL1131 from open pollinated cultivars were selected and recommended for cultivation in central Tarai.
\end{abstract}

Key words: hybrid cultivar, open pollinated cultivar, productivity

\section{Introduction}

Tomato (Solanum lycopersicon L.) is one of the most consumed vegetables in the world and is the second most important vegetable crop after potato (Panthee $\&$ Chen 2010). In Nepal tomato covers 16,416 ha whereas 2,910 ha in central Tarai (APSD 2012). It is a source of vitamin A, B, and C (Baloch 1994). It improves the income of the growers, generates employment in rural and urban areas and expands export potential (Ojha 2000). As compared to India ( $25 \mathrm{t} / \mathrm{ha})$ the productivity of this area $(17 \mathrm{t} / \mathrm{ha})$ is quite low (ICAR 2012, APSD 2012). Variety Lack of suitable tomato varieties under rice-based cropping system is one of the major contributing factors of low productivity. Farmers are growing open pollinated determinate as well as semi to indeterminate hybrid cultivars of tomato. There are many hybrid varieties in the market which are being grown by the farmers in central Tarai. Improved cultivars have many certainties on availability on time and required amount. Hence, our own suitable cultivars are required for wide cultivation. Tomato hybrid cultivar "Srijana" developed in Nepal was already tested, recommended and registered for foot hills to mid hills but not sufficient information from Tarai where few hybrids imported cultivars such as Makis, Manisha are widely on cultivation. HRDTOM-005XHRDTOM011(HT5XHT11) and HRDTOM-005XHRDTOM010 (HT5XHT10) are our own hybrid cultivars developed by Horticulture Research Division which need to have performance study in Tarai belt also. Beside this, farmers in Tarai have been cultivating determinate types of open pollinated cultivars.

Commercial hybrids in a number of crops like maize, sorghum, pearl millet, cotton, rice etc. have 
revolutionized the crop breeding programs (Melchinger 1993, Messmer et al. 1993). New genotypes must have potential for commercialization and must be able to withstand various biotic and abiotic stresses prevailing in the cultivating area.

The main objective of this study was to select suitable tomato hybrids and open pollinated cultivars in Tarai condition for rice-based cropping system.

\section{Methodology}

Three-week-old tomato seedlings of ten cultivars; three registered cultivars for check (CL- 1131 and Pusa Ruby from OP cultivars and Srijana from hybrid cultivar), eight superior cultivars from initial evaluation trial (IET) in the past were planted in November at RARS Parwanipur in rice harvested field. The experiment was laid out in randomized complete block design with four replications in $9 \mathrm{~m}^{2}$ plot size with $60 \times 60 \mathrm{~cm}$ row to row and plant to plant distance. Plants were grown with fertilizers 120:100:60 kg NPK and $15 \mathrm{t}$ compost per hectare during winter in 2005 , 2006, 2009 and 2010. Insecticide was sprayed as necessary and only one time foliar spray of fungicide was applied to save plants from heavy damage of lateblight disease. Tomato fruits were harvested frequently as shoulder portion partially matured. Plants of each cultivar were visually observed during their growth period for vegetative parameter; plant uniformity, plant vigor, plant height and ground coverage. Likewise, fruit parameters; fruit characteristics, maturity and fruit yield in number and weight were recorded. The fruits were harvested when ripened or changed in color.

\section{Results and Discussion Vegetative growth}

Plant uniformity ranged from 8 to 10 scores where cv. Manisha showed excellent plant uniformity. Plant uniformity was higher in hybrid cultivars. Bio-Rakshya and Pusa Ruby were more uniform among the OP cultivars. As far as plant vigor is concerned, the most vigorous cultivar was Manisha (9.8) followed by CL1131 (9.6). CL-1131 was most vigorous in both the years among OP cultivars whereas Manisha was most vigorous in first year and Srijana in second year. Overall, the hybrid cultivars were more vigorous than OP cultivars. Likewise, Srijana was tallest $(120.7 \mathrm{~cm})$ in height followed by Manisha $(113.5 \mathrm{~cm})$ and shortest was Bari-4 $(71 \mathrm{~cm})$ (Table 1). The trend of plant height in all the tested years were same in all the cultivars even though the effect of growing year was noticed but the plant height of Pusa Ruby in 2009 was quite taller. Most of the hybrid cultivars were taller than open pollinated cultivars except Makis. But it does not mean that hybrid cultivars should be taller or indeterminate. It depends on the character of parental lines of hybrid cultivars. The parental lines of Makis should be dwarf. Plant hairiness was highest in BioRakshya and Pusa Ruby (5) followed by Bari-5, CL1131 and Manisha (4) and least population of hairiness was noticed in HT5XHT10 (Table 1). Hairiness is a desirable character which inhibits sucking insects.

Table 1. Vegetative characters of 11 tomato cultivars at RARS Parwanipur $(2005,2006,2009,2010)$

\begin{tabular}{|c|c|c|c|c|c|c|c|c|c|c|c|c|}
\hline \multirow{2}{*}{$\begin{array}{l}\text { Cultivar } \\
\text { type }\end{array}$} & \multirow[t]{2}{*}{ Cultivars } & \multirow{2}{*}{$\begin{array}{l}\text { Plant- } \\
\text { Unifo- } \\
\text { mity }\end{array}$} & \multicolumn{3}{|c|}{ Plant vigory } & \multicolumn{5}{|c|}{ Plant height (cm) } & \multirow{2}{*}{$\begin{array}{l}\text { Plant } \\
\text { hairy- } \\
\text { ness } \\
(1-5)^{5}\end{array}$} & \multirow{2}{*}{$\begin{array}{l}\text { Mat- } \\
\text { urity }\end{array}$} \\
\hline & & & 2009 & 2010 & Wean & 2005 & 2006 & 2009 & 2010 & Thean & & \\
\hline \multirow{5}{*}{$\begin{array}{l}\text { Open } \\
\text { pollinated } \\
\text { cultivars }\end{array}$} & Bari-4 & 8 & 8 & 8 & 8 & 83 & 59 & - & - & 71 & 3.0 & $\mathrm{E}$ \\
\hline & Bio-Rakshya & 9 & 10 & 9 & 9.5 & 114 & 102 & - & - & 108 & 5.0 & $\mathrm{M}$ \\
\hline & Pusa Ruby & 9 & 9 & 8.7 & 8.8 & 105 & 122 & 123 & 96 & 111.5 & 5.0 & $\mathrm{E}$ \\
\hline & Bari-5 & 8 & 8 & 8 & 8 & 78 & 86 & 89 & - & 101 & 4.0 & E \\
\hline & CL-1131 & 8 & 10 & 9.3 & 9.6 & 81 & 134 & 83 & 97 & 98.7 & 4.0 & $\mathrm{~L}$ \\
\hline \multirow{8}{*}{$\begin{array}{l}\text { Hybrid } \\
\text { cultivars }\end{array}$} & HT5XHT11 & 9 & 9 & 8.7 & 8.8 & 128 & 113 & 81 & 106 & 107 & 3.0 & $\mathrm{E}$ \\
\hline & HT5XHT10 & 9 & 9 & 9.7 & 9.3 & 103 & 105 & 85 & 117 & 102.5 & 2.7 & $\mathrm{M}$ \\
\hline & Srijana & 9 & 9 & 10 & 9.5 & 130 & - & 105 & 127 & 120.7 & 3.3 & $\mathrm{M}$ \\
\hline & Marisha & 10 & 10 & 9.7 & 9.8 & 115 & - & - & 112 & 113.5 & 4.0 & $\mathrm{~L}$ \\
\hline & Makis & 9 & 9 & 8.3 & 8.6 & - & - & 85 & 91 & 88 & 3.0 & $\mathrm{M}$ \\
\hline & $\mathrm{CV} \%$ & 6.68 & - & 6.0 & 6.0 & - & 15.3 & 9.2 & 15.4 & & 16.2 & 23.3 \\
\hline & F-test $(0.05)$ & $n s$ & & $* *$ & & ns & $* *$ & & $* *$ & & $*$ & $* *$ \\
\hline & $\operatorname{LSD}(0.05)$ & 1.02 & & 0.89 & & & 23.3 & 15.3 & 24.9 & & .979 & \\
\hline
\end{tabular}

xPlant uniformity ; 1: unacceptable, 10: excellent y Plant vigor ; 1: poor, 10: vigorous

zPlant hairyness ; 1: none, 5: profuse

Maturity : E: early, M: Medium, L: late 


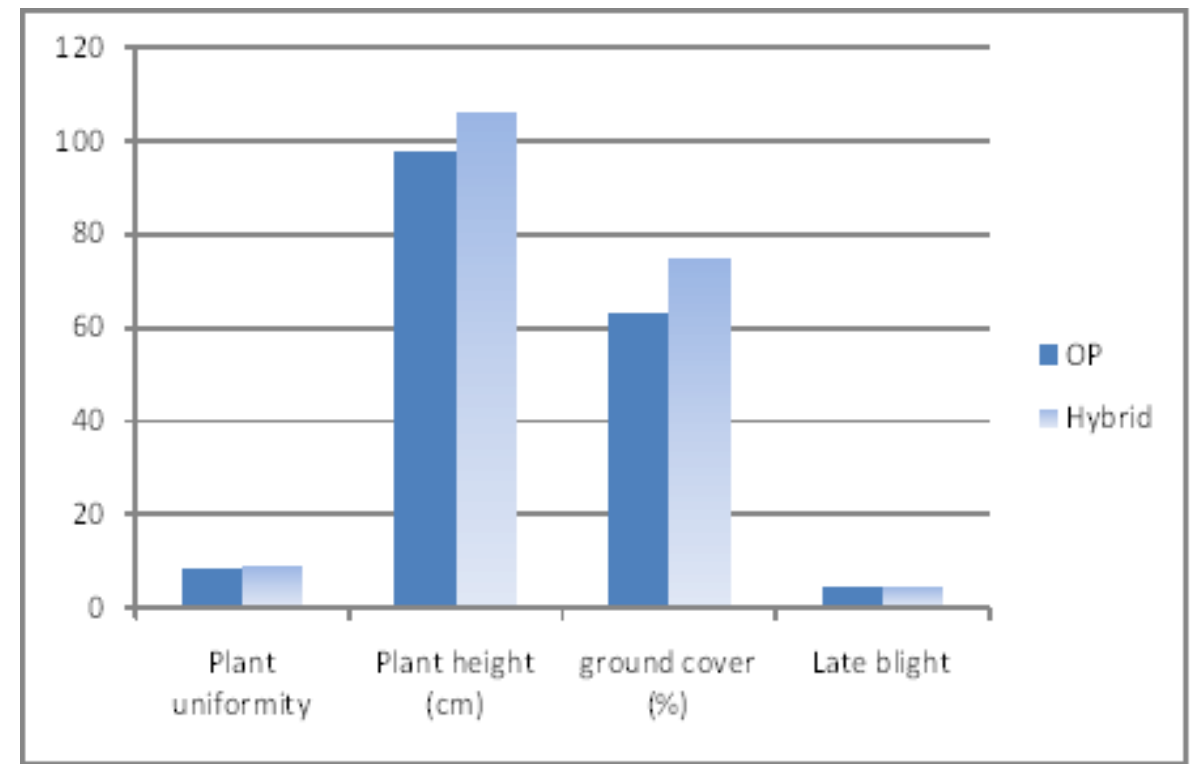

Fig. 1. OP vs hybrid cultivars on vegetative parameters

Among the tested cultivars, Bari-4, Pusa Ruby, Bari5 and HT5XHT10 matured earlier whereas CL-1131 and Manisha were late in maturity, and the rest were medium in maturity (Table 1). Ground coverage by the foliage was highest in Srijana (86\%) followed by HT5XHT11 (83\%) and HT5XHT10 (78\%) respectively whereas the lowest ground coverage was recorded in Manisha (53\%). Hence, ground coverage was higher in hybrid cultivars as compared to OP cultivars except Manisha. The reason behind this was that Manisha had erect growth habit. HT5XHT11 and Srijana had higher ground coverage in all the tested years whereas Bari-4 and CL-1131 had least ground coverage (Table 2). As far as late-blight disease was concerned Bio-Rakshya was least affected (3 score) followed by Bari-4, HT5XHT10 and Srijana. However, there was no any significant difference between hybrid and OP cultivars with respect to lateblight disease response (Table 2).

Table 2. Vegetative and fruit characters of 10 tomato cultivars at RARS Parwanipur $(2005,2006,2009,2010)$

\begin{tabular}{|c|c|c|c|c|c|c|c|c|c|c|}
\hline \multirow{2}{*}{$\begin{array}{l}\text { Type } \\
\text { cultivar }\end{array}$} & \multirow[t]{2}{*}{ Cultivars } & \multicolumn{4}{|c|}{ Ground coverage $(\%)$} & \multirow{2}{*}{$\begin{array}{l}\text { Fruit } \\
\text { Unifor- } \\
\text { mity }^{\pi}\end{array}$} & \multirow{2}{*}{$\begin{array}{l}\text { Late } \\
\text { blighty }\end{array}$} & \multicolumn{3}{|c|}{ Fruitsiplant (if) } \\
\hline & & 2005 & 2006 & 2009 & Mean & & & 2009 & 2010 & Mean \\
\hline \multirow{5}{*}{$\begin{array}{l}\text { Open } \\
\text { pollinated } \\
\text { cultivars }\end{array}$} & Bari-4 & 54 & 55 & 83 & 64.0 & 8 & 4 & 42 & - & 42 \\
\hline & Bio-Rakshya & 56 & 77 & 82 & 71.6 & 9 & 3 & 27 & - & 27 \\
\hline & Pusa Ruby & 59 & 61 & 100 & 73.3 & 9 & 5 & 54 & 38 & 46 \\
\hline & Bari-5 & 60 & 58 & 81 & 66.3 & 8 & 5 & 43 & - & 43 \\
\hline & CL-1131 & 46 & 44 & 100 & 63.3 & 9 & 5 & 53 & 47 & 50 \\
\hline \multirow{5}{*}{$\begin{array}{l}\text { Hybrid } \\
\text { cultivars }\end{array}$} & HT5XHT11 & 79 & 81 & 90 & 83.3 & 8 & 5 & 56 & 49 & 52.5 \\
\hline & HT5XHT10 & 77 & 60 & 97 & 78 & 8 & 4 & 42 & 70 & 57 \\
\hline & Srijana & 79 & - & 93 & 86 & 10 & 4 & 78 & 68 & 73 \\
\hline & Manisha & 53 & - & - & 53 & 10 & 5 & - & 22 & 22 \\
\hline & Makis & - & - & - & - & 10 & 5 & - & 30 & 30 \\
\hline $\begin{array}{l}\text { CV\% } \\
\text { F-test }(0.05)\end{array}$ & & $\begin{array}{l}11.0 \\
* * *\end{array}$ & $\begin{array}{l}10.8 \\
*\end{array}$ & $\begin{array}{l}11 \\
* * *\end{array}$ & & $\begin{array}{l}6.78 \\
* *\end{array}$ & $\begin{array}{l}14.9 \\
*\end{array}$ & $\begin{array}{l}15.6 \\
n s\end{array}$ & $\begin{array}{l}19.86 \\
* *\end{array}$ & \\
\hline $\operatorname{LSD}(0.05)$ & & 5.14 & 12.3 & 5.14 & & 1.086 & 1.29 & 15.6 & 13.91 & \\
\hline
\end{tabular}

${ }^{\mathrm{x}}$ fruit uniformity ; 1: unacceptable, 10: excellent, ${ }^{\mathrm{y}}$ Late blight; 1: none, 9: dead 


\section{Yield attributing characteristics}

Number of fruits per plant was highest in Srijana (73) followed by HT5XHT10 (57) and CL-1131 (50) whereas the least number of fruits per plant was in Manisha (22). Srijana had highest number of fruits per plant in the first year and second highest in second year. Generally the trend was higher the number of fruits per plant, smaller the size of fruits (Table 2). Hybrid cultivars provided more number of fruits per plant as compared to OP cultivars. However, it depended upon the purpose of hybrid development. As far as yield in terms of weight is concerned, hybrid cultivars gave higher yield (27.29 t/ha) as compared to OP cultivars $(19.41 \mathrm{t} / \mathrm{ha})$ that was 71 percent higher yield (Fig 2). It showed that hybrid cultivar could provide higher yield in Tarai also. The highest tomato yield (30.64 t/ha) was obtained from HT5XHT10 followed by Makis (28.90 t/ha) and Srijana (28.87 t/ ha) whereas the least yield was obtained from BioRakshya (14.68 t/ha) followed by Bari-5 (19.09 t/ha) respectively. No any hybrid cultivar gave lesser yield than OP cultivars except Manisha. HT5XHT10 and Srijana gave higher yield in all the tested years. Likewise, in OP cultivars, CL-1131 gave highest yield (22.08 t/ha) followed by Pusa Ruby (21.49 t/ha). However, Bari-5 had consistent yield and plant life was also short. Hybrid cultivars had a habit of bearing bigger size fruits than OP cultivars. Among the tested cultivars, Manisha gave bigger sized fruits (58 g) followed by Makis (40 g) and Pusa Ruby (36 g) respectively, whereas the smallest size fruits were obtained in Bari-5 (18.8 g) followed by Bari-4 (19.8 g) respectively (Table 3). Pokhrel and Bhattarai (2011) had reported an average weight of fruit $55.5 \mathrm{~g}$ and number of fruits per plant 167 in Srijana at western mid-hills under plastic house condition. But in this experiment at Tarai most of the cultivars had less weight and number of fruits per plant as compared to mid-hills (plastic house condition) because the crops were grown in open field at Parwanipur where the plants suffered frequently from drought and no any pruning and training done on plants. The In indeterminate type of cultivars, HT5XHT11, HT5XHT10 and Srijana produced a little bit smaller size fruits. One of the reasons behind this should be higher number of fruits per plant and indeterminate type of growth habit. Similarly, on the basis of yield per plant, HT5XHT10 was recorded as highest yielder (1853 g) followed by CL-1131 (1715 g), HT5XHT11 $(1702 \mathrm{~g})$ and Srijana (1697 g) respectively whereas the lowest yield per plant was obtained from BioRakshya (940 g) followed by Makis (1214 g) and Manisha (1230 g) respectively (Table 3$)$. Hence, CL1131 was a best OP variety for Terai in Parwnaipur condition.

Table 3. Yield (t/ha) of 10 tomato cultivars at RARS Parwanipur (2005, 2006, 2009, 2010)

\begin{tabular}{|c|c|c|c|c|c|c|c|c|c|c|c|c|}
\hline \multirow{2}{*}{$\begin{array}{l}\text { Types of } \\
\text { cultivar }\end{array}$} & \multirow[t]{2}{*}{ Cultivars } & \multicolumn{5}{|c|}{ Yield (t'ha) } & \multicolumn{3}{|c|}{ Av.fruit (g) } & \multicolumn{3}{|c|}{ Yield g/plt } \\
\hline & & 2005 & 2006 & 2009 & 2010 & Mean & 2009 & 2010 & Mean & 2009 & 2010 & Mean \\
\hline Open & Bari-4 & 17.8 & 18.3 & 23.24 & - & 19.78 & 19.8 & - & 19.8 & - & - & 1266 \\
\hline pollinated & Bio-Rakshya & 12.1 & 13.1 & 18.84 & - & 14.68 & 25.9 & - & 25.9 & - & - & 940 \\
\hline \multirow[t]{3}{*}{ cultivars } & Pusa Ruby & 12.9 & 16.0 & 32.65 & 24.43 & 21.49 & 42.0 & 31 & 36.5 & 2041 & 1152 & 1596 \\
\hline & Bari-5 & 17.9 & 16.8 & 22.58 & - & 19.09 & 18.8 & - & 18.8 & - & - & 1221 \\
\hline & CL-1131 & 10.1 & 14.0 & 35.79 & 28.41 & 22.07 & 44.0 & 25 & 34.5 & 2237 & 1193 & 1715 \\
\hline \multirow{8}{*}{$\begin{array}{l}\text { Hybrid } \\
\text { cultivars }\end{array}$} & HT5XHT11 & 20.6 & 23.7 & 33.48 & 31.25 & 27.26 & 37.0 & 27 & 32.0 & 2091 & 1313 & 1702 \\
\hline & HT5XHT10 & 19.9 & - & 33.19 & 38.83 & 30.64 & 35.0 & 23 & 29.0 & 2075 & 1631 & 1853 \\
\hline & Srijana & 21.6 & - & 32.32 & 32.69 & 28.87 & 29.0 & 20 & 24.5 & 2020 & 1373 & 1697 \\
\hline & Manisha & 12.4 & - & - & 29.28 & 20.84 & - & 58 & 58.0 & - & 1230 & 1230 \\
\hline & Makis & - & - & - & 28.90 & 28.90 & - & 40 & 40.0 & - & 1214 & 1214 \\
\hline & $\mathrm{CV} \%$ & 18.0 & & 32.7 & 15.10 & & & 16.83 & & 32.7 & 15.1 & \\
\hline & F-test $(0.05)$ & $* *$ & ns & Ns & $*$ & & & $* *$ & & $n c$ & $*$ & \\
\hline & $\operatorname{LSD}(0.05)$ & 2.2 & & 18.2 & 8.04 & & & 10.66 & & & 338 & \\
\hline
\end{tabular}




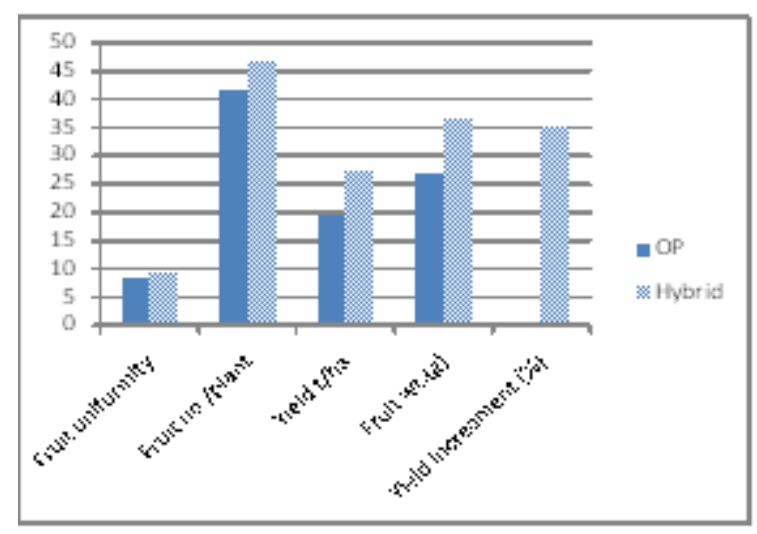

Fig. 2. OP vs hybrid cultivars on yield attributing characters

\section{Fruit characteristics}

Fruits of Pusa Ruby was oblate in shape whereas Bari4, Bari-5, Bio-Rakshya and HT5XHT10 were round shaped and the rest were oval shaped fruits. Generally consumers prefer oval shaped fruits for kitchen purpose in Nepal. Fruit bearing habit of Bio-Rakshya was bigger size, CL-1131 with small size and the rest were with medium size fruits. Color of matured fruits was red in all the cultivars but secondary color was yellow to orange. Fruit shoulder was distinct in Pusa Ruby and feebly developed in Bari-4, Bio-Rakshya, Bari-5, HT5XHT10 and Manisha whereas the rest of the cultivars had no any shoulder (Table 4).

Table 4. Fruit characteristics of 11 tomato cultivars

\begin{tabular}{l|l|l|l|l}
\hline Cultivar & Shape & Size & Color & Shoulder shape \\
\hline Bari-4 & Round & Medium & Orange red & Feebly developed \\
Bio-Rakshya & Round & Big & Orange red & Feebly developed \\
Pusa Ruby & Oblate & Medium & Red & distinct \\
Bari-5 & Round & Medium & Orange red & Feebly developed \\
CL-1131 & Oval & Small & Red & None \\
HT5XHT11 & Oval & Medium & Yellowish red & None \\
HT5XHT10 & Round & Medium & Orange red & Feebly developed \\
Srijana & Oval & Medium & Orange red & None \\
Marisha & Oval & Big & Yellowish red & Feebly developed \\
Makis & Oval & Medium & Yellowish red & None \\
\hline
\end{tabular}

On the basis of overall characteristics, cultivars, HRDTOM-005XHRDTOM-010, Makis and Srijana from hybrid cultivars and Bari-4 and CL-1131 from OP cultivars were selected and recommended for cultivation in central Terai.

\section{Acknowledgements}

We would like to acknowledge the Regional Agriculture Research Station, Parwanipur and our team supporting staff for providing facilities and help, and Horticulture Research Division, Khumaltar for providing genetic materials to conduct the research.

\section{References}

APSD. 2012. Statistical Information on Nepalese Agriculture. Agri-business Promotion and Statistics Division. Ministry of Agriculture, Singh Durbar, Kathmandu.

Baloach, F.A. 1994. Vegetable crops. In: Horticulture. National Book Foundation, Islamabad. pp.508.

ICAR. 2012. Vegetable statistics. Indian Institute of Vegetable Research. Indian Council of Agriculture Research. Varanasi-221305. Technical bulletin no. 51. pp. 77.
Melchinger, A.E. 1993. Use of RFLP markers for analysis of genetic relationships among breeding materials and prediction of hybrid performance. In: International Crop Science-I. (Eds. D.R. Buxton, R. Shibles, R.A. Forsberg, B.L. Blad, K.H. Asay, G.M. Paulson and R.F. Wilson) Crop Science Society of America, Madison, WI. pp.621-628.

Messmer, M.M., A.E. Melchinger, R. Hermann and J. Boppenmaier. 1993. Relationship among early European maize inbreds. II. Comparison of pedigree and RFLP data. Crop Sci. 33:944.

Ojha, B.R. 2004. Reproductive and fruit characterization of commercial genotypes of tomato (Solanum lycopersicon). NUTA Journal. 3(3) : 27-33.

Panthee, D.R. and F. Chen. 2010. Genomics of fungal disease resistance in tomato. Genomics 11(1):3039.

Pokhrel, T.R. and D. Bhattarai. 2011. Technology generation for tomato production under plastic house condition in different altitudes of Kaski district. In: Proceedings of the Seventh National Horticulture Seminar. Horticulture Research Division and Nepal Horticulture Society.Khumaltar, Lalitpur. pp.181-185. 
Nepal Journal of Science and Technology Vol. 15, No.2 (2014) 11-16 